\title{
Dr. Paul Delaunay zum 80. Geburtstag
}

Am 16. Februar 1958 feiert Dr. Paul Delaunay in Le Mans seinen 80. Geburtstag. Bei dieser Gelegenheit möchte auch Gesnerus dem Jubilar, der nicht nur der älteste, sondern auch der bedeutendste lebende französische Historiker der Medizin und Biologie ist, die herzlichsten Glückwünsche darbringen und den tiefen Dank aussprechen, zu dem die Historiker und Ärzte aller Länder dem unermüdlichen Forscher verpflichtet sind.

Wenn man die lange Reihe von Büchern, Broschüren und Artikeln überschaut, die Dr. Delaunay seit 1901 veröffentlicht hat, möchte man es kaum glauben, daß sie nur Nebenprodukte eines angestrengten Arztdaseins sind. Und doch hat der Verfasser über 40 Jahre lang in Le Mans praktiziert, nachdem er in Paris studiert hatte und von 1900 bis 1905 Interne in fünf Spitälern der Hauptstadt gewesen war.

Dr. Delaunay hat sich in gleichem Maße dem Studium von Persönlichkeiten, Institutionen und Ideen gewidmet. Manche seiner Bücher sind «Klassiker» geworden, wie Le Monde Médical Parisien au XVIII ${ }^{e}$ Siècle (Paris 1905), La Maternité de Paris 1625-1907 (Paris 1909), Pierre Belon Naturaliste (Le Mans 1926), La Vie Médicale au XVI ${ }^{e}, X V I I^{e}$ et XVIII ${ }^{e}$ Siècles (Paris 1935), La Médecine et l'Eglise (Paris 1948). Seine zahlreichen wertvollen Arbeiten zur lokalen Medizingeschichte seiner Heimat sind zum Glück in Sammelbänden Vieux Médecins Mayennais (2 Bände) und Vieux Médecins Sarthois (3 Bände) zusammengefaßt worden. Besondere Aufmerksamkeit verdienen auch seine Studien über die französische Medizin zu Beginn des 19. Jahrhunderts, von denen hier nur Les Médecins, la Restauration et la Révolution de 1830 (1932), L'Evolution des Théories et de la Pratique Médicales 1789-1848 und die zwei Sammelbände Etudes d'Histoire et de Biographie Médicales (Le Mans 1929 und 1932) erwähnt werden sollen.

Auf eine solche Leistung können der Verfasser mit Stolz, die Mit- und Nachwelt nur mit Bewunderung blicken. Dabei wissen alle die, denen es vergönnt ist, Dr. Delaunay persönlich zu kennen, von seiner großen Bescheidenheit und unbegrenzten Hilfsbereitschaft. Zu ihrer Freude haben sie in ihm in vermehrtem Maße die Züge wiedergefunden, die schon in seinem Werk hervortreten: außerordentliche Gelehrsamkeit, Ideenreichtum, menschliche Wärme und trockener Humor.

Möge es Dr. Delaunay beschieden sein, die wichtigen biologiegeschichtlichen Studien, an denen er seit Jahren für Unesco arbeitet, zu Ende zu führen und noch viele schöne Jahre im Kreise seiner treusorgenden Familie zu verbringen.

Erwin H. Ackerknecht 